\title{
Evaluation of the Morphology and Osteogenic Potential of Titania-Based Electrospun Nanofibers
}

\author{
Xiaokun Wang, ${ }^{1}$ Jingxian Zhu, ${ }^{2}$ Ling Yin, ${ }^{1}$ Shize Liu, ${ }^{1}$ Xin Zhang, \\ Yingfang Ao, ${ }^{2}$ and Haifeng Chen ${ }^{1}$ \\ ${ }^{1}$ Department of Biomedical Engineering, College of Engineering, Peking University, No. 5 Yiheyuan Road, Haidian District, \\ Beijing 100871, China \\ ${ }^{2}$ Institute of Sports Medicine, Peking University Third Hospital, 49 North Garden Road, Haidian District, Beijing 100191, China
}

Correspondence should be addressed to Haifeng Chen, haifeng.chen@pku.edu.cn

Received 8 February 2012; Accepted 3 April 2012

Academic Editor: Krasimir Vasilev

Copyright (c) 2012 Xiaokun Wang et al. This is an open access article distributed under the Creative Commons Attribution License, which permits unrestricted use, distribution, and reproduction in any medium, provided the original work is properly cited.

\begin{abstract}
Submicron-scale titania-based ceramic fibers with various compositions have been prepared by electrospinning. The as-prepared nanofibers were heat-treated at $700^{\circ} \mathrm{C}$ for $3 \mathrm{~h}$ to obtain pure inorganic fiber meshes. The results show that the diameter and morphology of the nanofibers are affected by starting polymer concentration and sol-gel composition. The titania and titaniasilica nanofibers had the average diameter about 100-300 $\mathrm{nm}$. The crystal phase varied from high-crystallized rutile-anatase mixed crystal to low-crystallized anatase with adding the silica addition. The morphology and crystal phase were evaluated by SEM and XRD. Bone-marrow-derived mesenchymal stem cells were seeded on titania-silica 50/50 fiber meshes. Cell number and early differentiation marker expressions were analyzed, and the results indicated osteogenic potential of the titania-silica 50/50 fiber meshes.
\end{abstract}

\section{Introduction}

The design and preparation of nanoscale fine structures have attracted great attention because of their potential unique properties and applications. The electrospinning technique has been reported to be a simple and versatile method to produce fibrous structure with nanoscale to microscale dimensions from synthetic and natural polymers [1-5]. Moreover, the principles of electrospinning technique have been expanded to the ceramic and metal oxide systems [69]. The morphology and properties of the nanofibers depend on the concentration of polymer solutions, solvent, applied electric field strength, and deposition distance [10-12].

There are many studies focusing on applying electrospun fibrous scaffolds to bone tissue engineering [13, 14]. Most of the electrospun scaffolds are made of polymers or polymerceramic nanoparticle composite, and a few studies have been done on pure ceramic scaffolds [15-18]. Titania is well known as biocompatible surface of titanium implants, and, as the major component of bioglass, silica is also considered to have good biology performance. A number of methods have been applied to produce titania-silica nanostructures, including the sol-gel process [19], plasma-spraying [20], and chemical vapor deposition [21]. Many previous studies of nanostructured titania-silica materials focus on their optical properties, high thermal stability, and high surface area properties, and this material has been widely used as optical chemical sensors [22], supporting materials [23], and catalysts [24]. In the aspect of their biology performance, most of the applications of nanostructured titania-silica materials in the field of biomedical engineering are using titania-silica as coating material or fillers for composite scaffolds [25-29].

Recent research has showed that electrospun titania nanofibers have the osteoinductive potentials, and the effects of surface roughness on MG63 osteoblast-like cells were also discussed [30]. However, few researches are available that give an insight into how titania-silica nanofibers influence cell responses. Therefore, the aim of this study is to characterize the morphology of electrospun titania-based fibers and evaluate bone-derived mesenchymal stem cell (MSC) responses and osteoinductivity of titania-silica fibers 


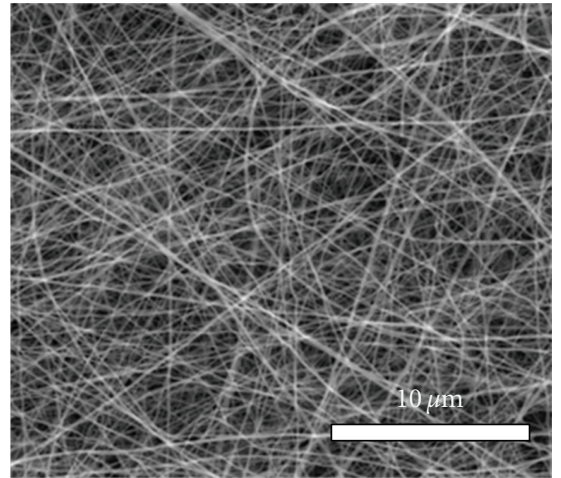

(a)

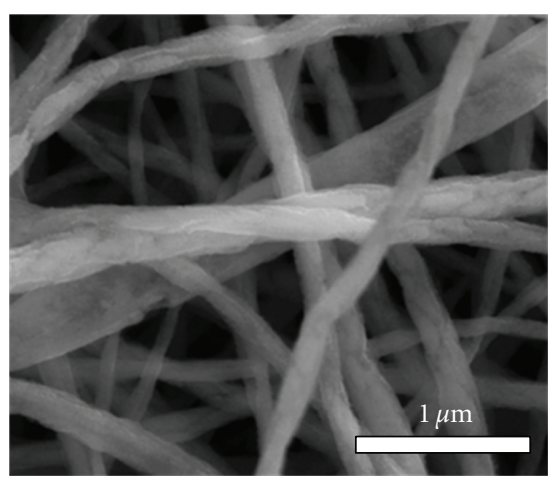

(d)

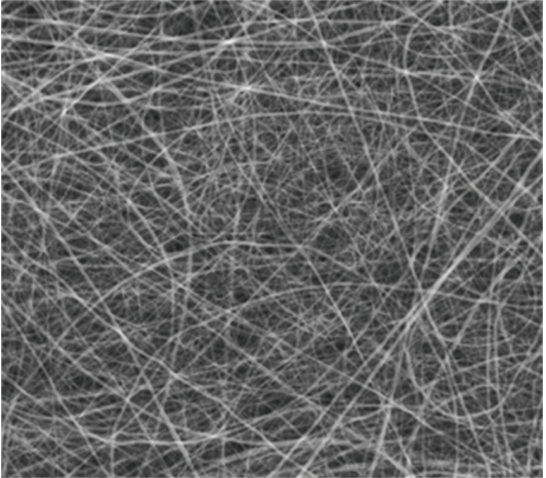

(b)

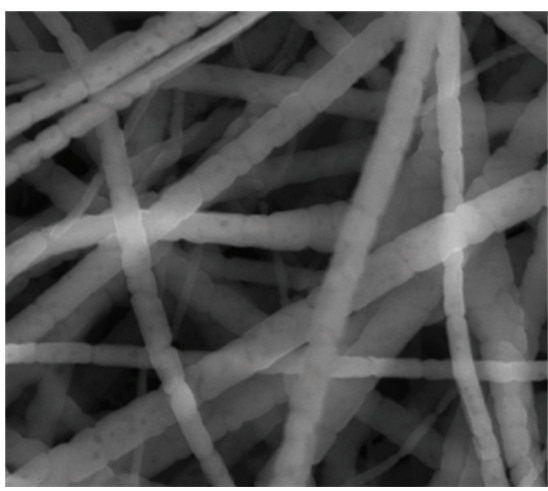

(e)

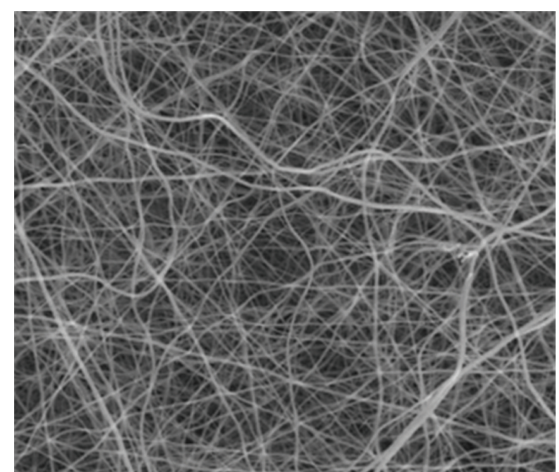

(c)

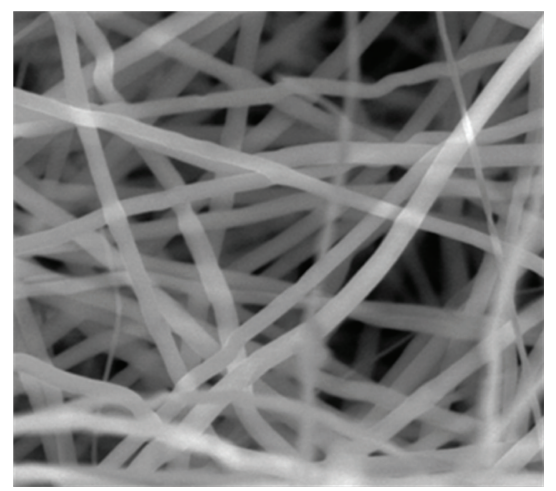

(f)

FIGURE 1: SEM images and analysis of the morphology of the electrospun nanofiber meshes produced with $((\mathrm{a}),(\mathrm{d})) 6 \% \mathrm{PVP}$ TiO $2,((\mathrm{~b}),(\mathrm{e}))$ $10 \% \mathrm{PVP} \mathrm{TiO}_{2}$, ((c),(f)) 10\% $\mathrm{PVP} \mathrm{TiO}_{2}-\mathrm{SiO}_{2}$ 50/50.

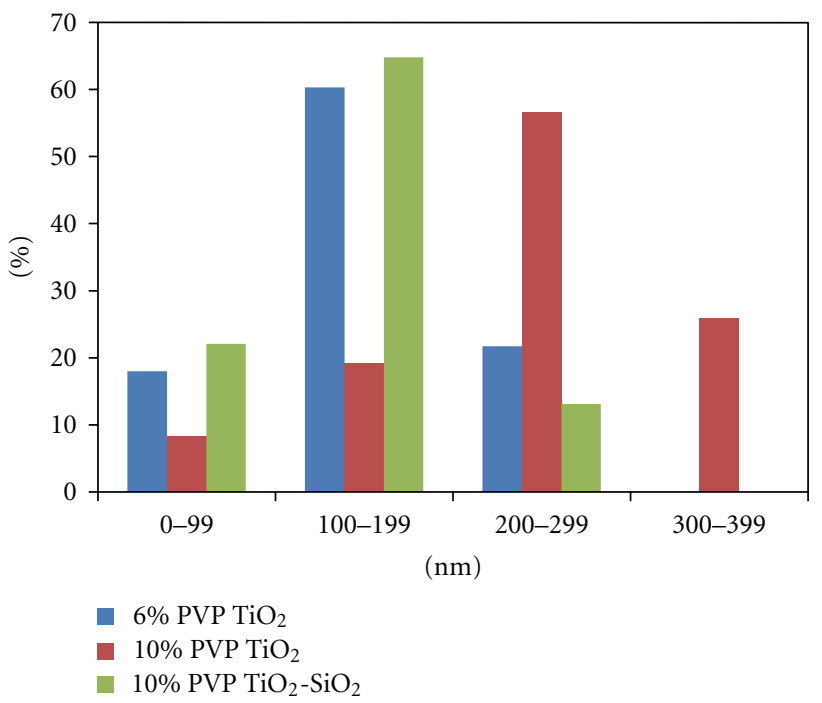

Figure 2: Histogram of diameter distribution of nanofibers on the meshes.

to determine their potential application as a scaffold material for bone tissue engineering.

\section{Materials and Methods}

2.1. Fabrication of Titania and Titania-Silica Nanofibers. The titania and titania-silica fibrous meshes were prepared from titanium(IV) isopropoxide (TiP), tetraethyl orthosilicate (TEOS), poly(vinyl pyrrolidone) (PVP, $M_{w} \approx 1300000$ ), and acetic acid. In a typical procedure, $0.5 \mathrm{~mL}$ of TiP was mixed with $0.5 \mathrm{~mL}$ ethanol and $0.5 \mathrm{~mL}$ acetic acid. After $10 \mathrm{~min}$ stirring, the sol was added to $1.5 \mathrm{~mL} 6 \%$ and $10 \%$ PVP ethanol solution, followed by magnetic stirring for $30 \mathrm{~min}$. The starting solution of titania-silica fibers was made of sol containing $0.25 \mathrm{~mL}$ of TiP and $0.25 \mathrm{~mL}$ TEOS mixed with $0.5 \mathrm{~mL}$ ethanol and $0.5 \mathrm{~mL}$ acetic acid. Then the sol was added to $1.5 \mathrm{~mL} 10 \%$ PVP ethanol solution. In the electrospinning setup, the collection distance was $10 \mathrm{~cm}$, and the applied voltage was $8 \mathrm{kV}$. The electrospun fibers were collected on the flat plate. Finally, the PVP was removed from these fibers by heating them in air at $700^{\circ} \mathrm{C}$ for $3 \mathrm{~h}$.

Sample topography and cell morphology were examined by scanning electron microscopy (Hitachi S-4800) using a $15 \mathrm{kV}$ accelerating voltage. Fiber diameter distribution was evaluated by image analysis software (ImageJ, NIH software) from three SEM images of at least two different samples. Fiber diameter was evaluated from at least 150 fibers at $16,000 x$ magnification. 
The chemical composition of the scaffolds was examined by XPS (Axis Ultra by Kratos Analytical Ltd.) of at least two different samples with 3 spots per sample. Additionally, crystal structure X-ray diffraction (XRD) was investigated by RAPID-S (Rigaku Denkico Co., Ltd.)

2.2. Cell Culture. Bone-derived mesenchymal stem cells were extracted from two lower extremities of a Wistar rat with approval of the animal ethics committee of the Peking University Third Hospital. Briefly, the adherent soft tissues of bones were cleaned, and epiphyses were removed with a scissor. The marrow was harvested by inserting a syringe needle (16-gauge) into each end of the bone and flushing repeatedly with phosphate-buffered saline (PBS) supplemented with $100 \mathrm{U} / \mathrm{mL}$ penicillin and streptomycin into a $100 \mathrm{~mm}$ culture dish. Cell suspension was obtained by drawing the marrow into a $20 \mathrm{~mL}$ syringe through 22 -gauge needles. The cells were then centrifuged, counted, seeded at a density of $1 \times 10^{6}$ in $8 \mathrm{~mL}$ of $\alpha$-MEM (Minimal Essential Medium) with $10 \%$ fetal bovine serum (FBS), $100 \mathrm{U} / \mathrm{mL}$ penicillin, and streptomycin per $100 \mathrm{~mm}$ culture dish, and cultured at $37^{\circ} \mathrm{C}$ in a humidified atmosphere of $95 \%$ air and $5 \% \mathrm{CO}_{2}$. Nonadherent cells were removed at 3 days after seeding by changing the medium; thereafter, the medium was changed every 3 days. Cells of the 3 rd to the 5 th passage were used for further study.

For cell culture on the titania-silica 50/50 meshes, MSCs were cultured in osteogenic media, containing Dulbecco's modified Eagle medium, containing 10\% fetal bovine serum (FBS) and $1 \%$ penicillin and streptomycin, $0.1 \mu \mathrm{mol} / \mathrm{L}$ dexamethasone, $10 \mathrm{mmol} / \mathrm{L} \beta$-sodium glycero-phosphate, and $50 \mu \mathrm{mol} / \mathrm{L}$ ascorbic acid phosphate, at $37^{\circ} \mathrm{C}$ in $5 \% \mathrm{CO}_{2}$ and $100 \%$ humidity. Cells were grown on 12 -well plate tissue culture polystyrene and titania-silica 50/50 meshes, at a density of 10,000 cells $/ \mathrm{cm}^{2}$. MSCs were fed every $48 \mathrm{~h}$ and harvested at Day 3 and Day 7. RNA was extracted by using Qiagen's RNeasy Mini Kit and reverse-transcribed by using the Qiagen-Omniscript RT kit as per the manufacturer's directions. RT-PCR and Real time PCR were performed for Runx2 (NCBI accession no. NM_009820.2) and ALP (NCBI accession no. NM_007431). Optimal oligonucleotide primers were designed by using Primer Express 2.0 software and purchased from Sigma-Geosys. Data were normalized to the endogenous reference gene GAPDH (NCBI accession no. NM_008084).

\section{Results}

Figure 1 shows the SEM images of electrospun fibers. These images reveal that fibers have diameters varying from around $100 \mathrm{~nm}$ to $300 \mathrm{~nm}$. Under lower magnification (Figures 1(a), $1(\mathrm{c})$, and $1(\mathrm{e})$ ), fibers in each group were evenly distributed in general, and higher-magnification images (Figures 1(b), $1(\mathrm{~d})$, and $1(\mathrm{f})$ ) revealed more detailed structures of the fiber. Comparing Figures 1(b) and 1(d), it is observed that the average diameter of fibers increases with the increasing starting polymer concentration. Also, even using the same concentration of starting polymer, pure titania meshes
TABLe 1: Elemental composition \pm standard deviation (SD) of electrospun meshes analyzed by XPS.

\begin{tabular}{lcccc}
\hline & $\mathrm{Ti}$ & $\mathrm{Si}$ & $\mathrm{O}$ & $\mathrm{C}$ \\
\hline $6 \% \mathrm{PVP}^{-\mathrm{TiO}_{2}}$ & $21.4 \pm 0.8$ & $2.5 \pm 1.1$ & $61.2 \pm 3.1$ & $13.8 \pm 1.1$ \\
$10 \% \mathrm{PVP}^{-\mathrm{TiO}_{2}}$ & $22.5 \pm 1.2$ & $2.3 \pm 0.9$ & $63.4 \pm 2.3$ & $12.7 \pm 1.8$ \\
$10 \% \mathrm{PVP}-\mathrm{TiO}_{2}-\mathrm{SiO}_{2}$ & $15.3 \pm 0.4$ & $14.6 \pm 0.9$ & $60.1 \pm 2.1$ & $9.9 \pm 1.3$ \\
\hline
\end{tabular}

have thicker fibers than titania-silica 50/50 hybrid meshes (Figures 1(d) and 1(f)). Beside the diameter, the existence of silica also has influences on fiber surface morphology. Figure 1(d) shows that pure titania fibers form of titania crystal clusters and the titania-silica 50/50 fibers (Figure 1(f)) have smoother surfaces.

Figure 2 shows the diameter distribution of calcined fibers analyzed by ImageJ. It confirms the observation of SEM images, which is 6\% PVP titania fibers, and 10\% PVP titania-silica 50/50 fibers have thinner diameter than $10 \%$ PVP titania fibers.

Chemical analysis by XPS (Table 1) showed no N, indicating PVP was removed thoroughly by the heat treatment. 6\% PVP and 10\% PVP titania fiber meshes were generally composed by $\mathrm{Ti}, \mathrm{O}$, and small amount of silica as well. The titania-silica 50/50 fiber mesh has $\mathrm{Ti}, \mathrm{Si}$, and $\mathrm{O}$, and the ratio of Ti to Si was $1: 1$, consistent with the initial molar ratio of TiP to TEOS.

Typical XRD patterns of titania fibers and titania-silica 50/50 fibers with heat treatment are shown in Figure 3. Two groups of titania fibers have similar spectra, which is presented in Figure 3(a). The peaks of rutile and anatase crystal structures were found in the two groups of pure titania fibers. For titania-silica 50/50 fibers, only the peaks of anatase were found and the peak intensity of hybrid fibers was also weaker than that of pure titania fibers.

MSC morphology on titania-silica 50/50 fiber meshes was observed by SEM and confocal microscope. The cells grew throughout the surfaces with elongated morphology (Figures 4(a) and 4(b)). Cell number on fibrous mesh groups was lower than that on TCPs. However, Runx2 and alkaline phosphatase gene expressions were affected in the opposite way, with cells on the hybrid mesh groups having the higher level of relative gene expression (Figures 5(a) -5(c)). In general, the cell behavior was sensitive to the fibrous surface.

\section{Discussion}

In this study, pure titania and titania-silica 50/50 ceramic fibrous meshes were made by electrospinning process, and MSC responses on titania-silica fibers were evaluated.

Factors which can influence the fiber diameter and fiber morphology of electrospun nanofibers were discussed in previous studies $[10,11]$. The concentration of starting polymer solution is the most commonly used method to adjust the electrospun fiber diameter. Generally, increasing polymer concentration is one of the major methods to increase electrospun fiber diameter [11]. For the pure ceramic electrospun fibers which need heat treatment to 


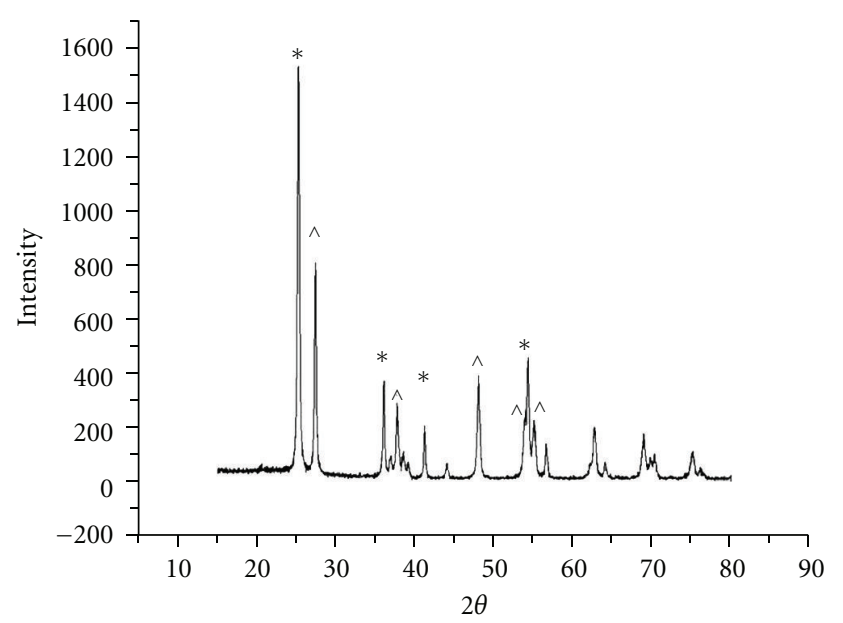

(a)

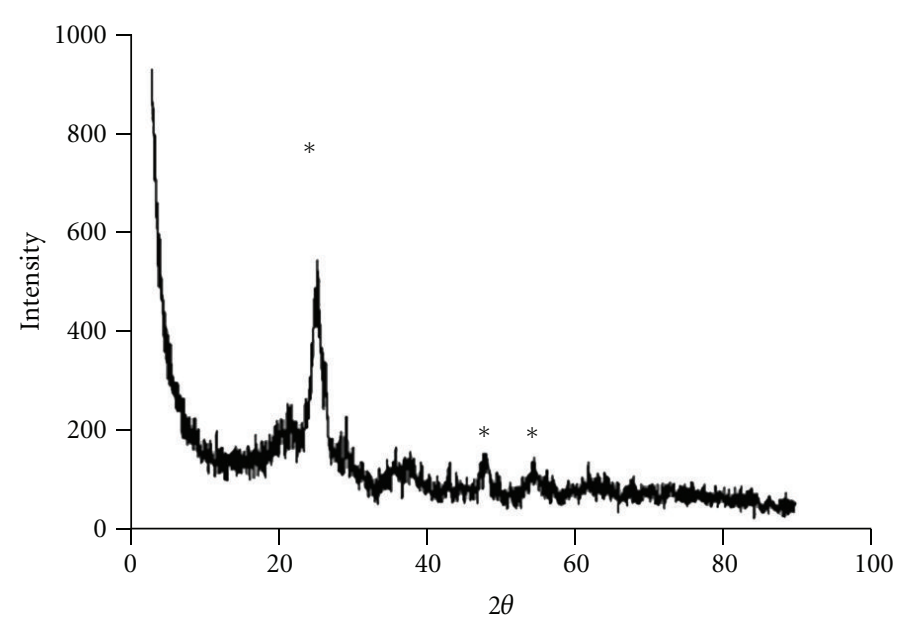

(b)

Figure 3: XRD spectra of (a) $\mathrm{TiO}_{2}$ meshes and (b) titania-silica 50/50 meshes. Respective rutile $\left(^{\wedge}\right)$ and anatase $\left(^{*}\right)$ reference peaks are marked according to JCPDS database.

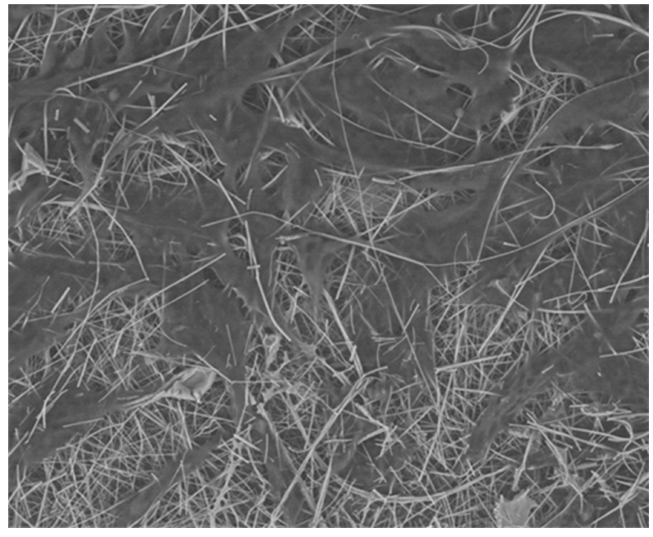

(a)

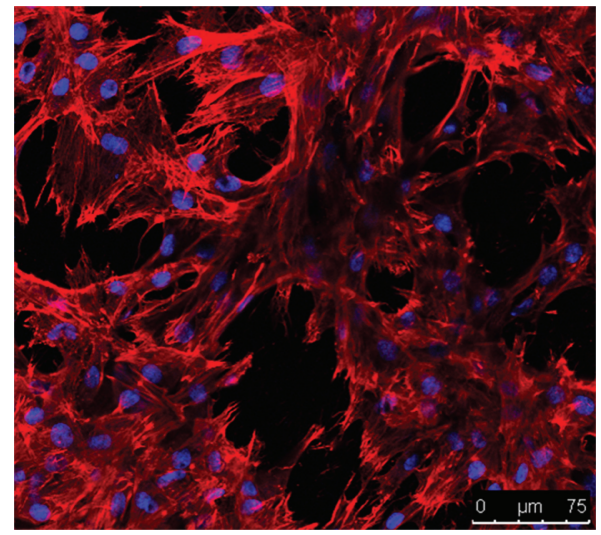

(b)

FIgURE 4: SEM (a) and confocal microscope (b) images of the morphology of MSCs cultured on the titania-silica 50/50 meshes.

remove the polymer component, the sol-gel content and calcination temperature can also contribute to fiber morphology [31]. SEM images show that 10\% PVP titania meshes have thicker fiber diameter than 6\% PVP titania meshes; the result is consistent with previous study [30]. When silica is added into the sol-gel system, even with the same concentration of starting polymer and same gel content, the fiber diameter is thinner than pure titania fibers. In addition, the addition of silica had influence on fiber surface morphology, too. The surface of titania-silica fiber is smoother than that of pure titania fiber. This result is further supported by XRD spectrum, which shows that titania-silica has lower degree of crystallization under the same calcination temperature. After heating up to $700^{\circ} \mathrm{C}$ for $3 \mathrm{~h}$, two groups of pure titania fibers formed rutile-anatase mixed crystals while titania-silica 50/50 fibers formed not well-crystalized anatase crystals. Similar results were reported by heating the mixture of silica and titania nanoparticles [32], which shows that the addition of silica affects crystal phase transformation of titania-silica particles. XPS results with the lack of $\mathrm{N}$ support the point that PVP was removed during calcination and the substrates are composed of silica and titania. The small amount of silica in titania fibers may be caused by calcining the fiber meshes on a silicon wafer.

Cell number on the meshes was affected by the fibrous structure of the titania-silica meshes, which had lower cell number than TCPs. This effect of fibrous surfaces and rough surfaces on cell number has been previously reported by many studies for $\mathrm{Ti} / \mathrm{TiO}_{2}$ surfaces that promote osteoblast or MSCs differentiation toward osteoblast [30, 33, 34]. Beside cell number, the differentiation of MSCs was also affected by surface structure. Runx2, a transcription factor belonging to the Runx family, determines the osteoblast lineage from multipotent MSCs. Runx2 induces osteoblastic differentiation at early stage [35]. The relative gene expression of Runx2 of this study is significantly higher than control. Also alkaline-phosphatase-specific activity, which is also an early marker of osteogenic differentiation, was significantly higher 


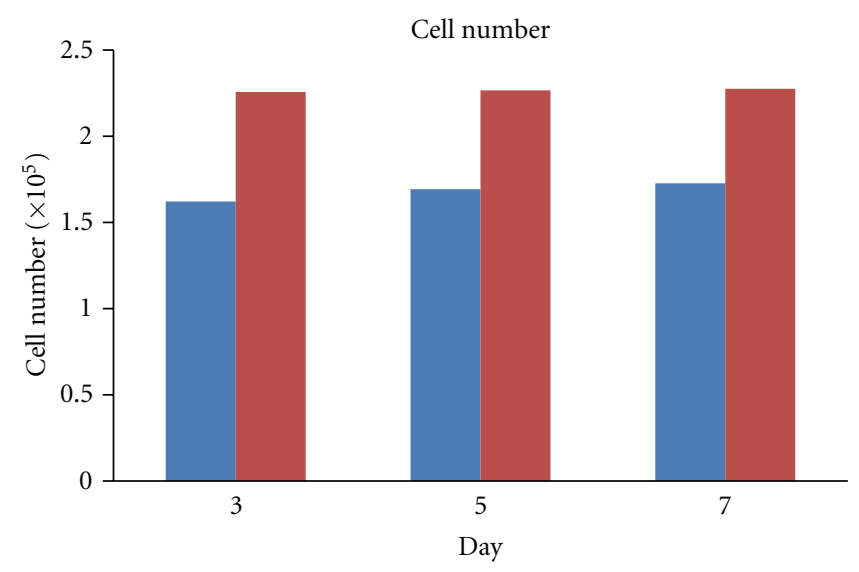

(a)

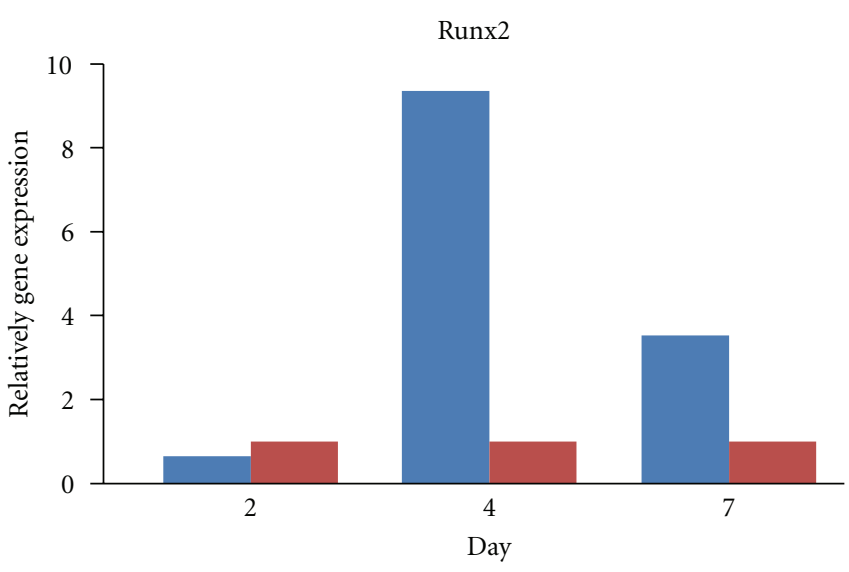

(b)

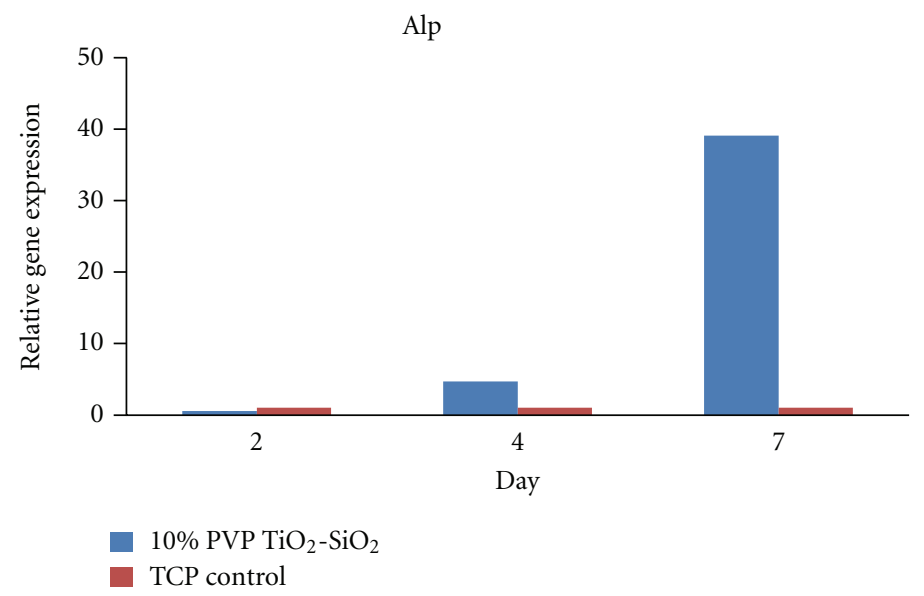

(c)

FIGURE 5: Effects of titania-silica 50/50 nanofibers on cell number and mRNA expression in MSCs. (a) Cell number, (b) Runx2, (c) alkaline phosphatase.

in titania-silica 50/50 when compared to the TCP control. The cell results show that titania-silica 50/50 fiber meshes have osteogenic potential.

\section{Conclusion}

In this study, submicron-scale composite fiber titania-based ceramics with various compositions have been prepared by electrospinning. Pure ceramic fibers were obtained by heat treatment at $700^{\circ} \mathrm{C}$ for $3 \mathrm{~h}$. SEM images showed that the diameter and morphology of the nanofibers were influenced by starting polymer concentration and sol composition. The titania and titania-silica nanofibers have the average diameter around $100 \sim 300 \mathrm{~nm}$. The fiber surface morphology and crystal phase were influenced by silica content. Bone-marrow-derived MSCs were seeded on titania-silica 50/50 fiber meshes. Cell number and early differentiation marker expressions were analyzed, and the results indicate osteogenic potential of the titania-silica 50/50 fiber meshes. In conclusion, the present work has shown that both the morphology and crystal phase of titania-based electrospun nanofibers are able to be controlled by starting polymer concentration and chemical composition. And these titaniabased electrospun nanofibers may have potential use as a new scaffold material for bone tissue engineering.

\section{Acknowledgments}

The work is supported by the Ministry of Science and Technology of China (Grants 2012CB933903, 2011AA030102) and the Wallace H. Coulter Foundation.

\section{References}

[1] B. Ding, H. Y. Kim, S. C. Lee et al., "Preparation and characterization of a nanoscale poly(vinyl alcohol) fiber aggregate produced by an electrospinning method," Journal of Polymer Science, Part B, vol. 40, no. 13, pp. 1261-1268, 2002.

[2] Y. Z. Zhang, J. Venugopal, Z. M. Huang, C. T. Lim, and S. Ramakrishna, "Crosslinking of the electrospun gelatin nanofibers," Polymer, vol. 47, no. 8, pp. 2911-2917, 2006.

[3] M. T. Hunley and T. E. Long, "Electrospinning functional nanoscale fibers: a perspective for the future," Polymer International, vol. 57, no. 3, pp. 385-389, 2008. 
[4] I. Keun Kwon, S. Kidoaki, and T. Matsuda, "Electrospun nanoto microfiber fabrics made of biodegradable copolyesters: structural characteristics, mechanical properties and cell adhesion potential," Biomaterials, vol. 26, no. 18, pp. 3929-3939, 2005.

[5] F. Yang, R. Murugan, S. Wang, and S. Ramakrishna, "Electrospinning of nano/micro scale poly(l-lactic acid) aligned fibers and their potential in neural tissue engineering," Biomaterials, vol. 26, no. 15, pp. 2603-2610, 2005.

[6] D. Li, Y. Wang, and Y. Xia, "Electrospinning of polymeric and ceramic nanofibers as uniaxially aligned arrays," Nano Letters, vol. 3, no. 8, pp. 1167-1171, 2003.

[7] R. Ramaseshan, S. Sundarrajan, R. Jose, and S. Ramakrishna, "Nanostructured ceramics by electrospinning," Journal of Applied Physics, vol. 102, no. 11, pp. 1063-1080, 2007.

[8] M. Macías, A. Chacko, J. P. Ferraris, and K. J. Balkus Jr., "Electrospun mesoporous metal oxide fibers," Microporous and Mesoporous Materials, vol. 86, no. 1-3, pp. 1-13, 2005.

[9] X. Wang, C. Drew, S. H. Lee, K. J. Senecal, J. Kumar, and L. A. Samuelson, "Electrospun nanofibrous membranes for highly sensitive optical sensors," Nano Letters, vol. 2, no. 11, pp. 12731275, 2002.

[10] J. Doshi and D. H. Reneker, "Electrospinning process and applications of electrospun fibers," Journal of Electrostatics, vol. 35, no. 2-3, pp. 151-160, 1995.

[11] W. K. Son, J. H. Youk, T. S. Lee, and W. H. Park, "The effects of solution properties and polyelectrolyte on electrospinning of ultrafine poly(ethylene oxide) fibers," Polymer, vol. 45, no. 9, pp. 2959-2966, 2004.

[12] P. Gupta, C. Elkins, T. E. Long, and G. L. Wilkes, "Electrospinning of linear homopolymers of poly(methyl methacrylate): exploring relationships between fiber formation, viscosity, molecular weight and concentration in a good solvent," Polymer, vol. 46, no. 13, pp. 4799-4810, 2005.

[13] C. Li, C. Vepari, H. J. Jin, H. J. Kim, and D. L. Kaplan, "Electrospun silk-BMP-2 scaffolds for bone tissue engineering," Biomaterials, vol. 27, no. 16, pp. 3115-3124, 2006.

[14] W. J. Li, C. T. Laurencin, E. J. Caterson, R. S. Tuan, and F. K. Ko, "Electrospun nanofibrous structure: a novel scaffold for tissue engineering," Journal of Biomedical Materials Research, vol. 60, no. 4, pp. 613-621, 2002.

[15] S. R. Bhattarai, N. Bhattarai, H. K. Yi, P. H. Hwang, D. I. Cha, and H. Y. Kim, "Novel biodegradable electrospun membrane: scaffold for tissue engineering," Biomaterials, vol. 25, no. 13, pp. 2595-2602, 2004.

[16] Y. Zhang, J. R. Venugopal, A. El-Turki, S. Ramakrishna, B. $\mathrm{Su}$, and C. T. Lim, "Electrospun biomimetic nanocomposite nanofibers of hydroxyapatite/chitosan for bone tissue engineering," Biomaterials, vol. 29, no. 32, pp. 4314-4322, 2008.

[17] Y. Ito, H. Hasuda, M. Kamitakahara et al., "A composite of hydroxyapatite with electrospun biodegradable nanofibers as a tissue engineering material," Journal of Bioscience and Bioengineering, vol. 100, no. 1, pp. 43-49, 2005.

[18] S. Sakai, Y. Yamada, T. Yamaguchi, and K. Kawakami, "Prospective use of electrospun ultra-fine silicate fibers for bone tissue engineering," Biotechnology Journal, vol. 1, no. 9, pp. 958-962, 2006.

[19] S. Z. Chu, S. Inoue, K. Wada, D. Li, H. Haneda, and S. Awatsu, "Highly porous $\left(\mathrm{TiO}_{2}-\mathrm{SiO}_{2}-\mathrm{TeO}_{2}\right) / \mathrm{Al}_{2} \mathrm{O}_{3} / \mathrm{TiO}$ composite nanostructures on glass with enhanced photocatalysis fabricated by anodization and sol-gel process," Journal of Physical Chemistry B, vol. 107, no. 27, pp. 6586-6589, 2003.
[20] M. F. Morks, "Plasma spraying of zirconia-titania-silica bioceramic composite coating for implant application," Materials Letters, vol. 64, no. 18, pp. 1968-1971, 2010.

[21] R. Leboda, V. V. Turov, M. Marciniak, A. A. Malygin, and A. A. Malkov, "Characteristics of the hydration layer structure in porous titania-silica obtained by the chemical vapor deposition method," Langmuir, vol. 15, no. 24, pp. 8441-8446, 1999.

[22] T. H. Tran-Thi, R. Dagnelie, S. Crunaire, and L. Nicole, "Optical chemical sensors based on hybrid organic-inorganic sol-gel nanoreactors," Chemical Society Reviews, vol. 40, no. 2, pp. 621-639, 2011.

[23] K. M. S. Khalil, A. A. Elsamahy, and M. S. Elanany, "Formation and characterization of high surface area thermally stabilized titania/silica composite materials via hydrolysis of titanium(IV) tetra-isopropoxide in sols of spherical silica particles," Journal of Colloid and Interface Science, vol. 249, no. 2, pp. 359-365, 2002.

[24] X. Zhang, F. Zhang, and K. Y. Chan, "Synthesis of titaniasilica mixed oxide mesoporous materials, characterization and photocatalytic properties," Applied Catalysis A, vol. 284, no. 12, pp. 193-198, 2005.

[25] V. Ääritalo, S. Areva, M. Jokinen, M. Lindén, and T. Peltola, "Sol-gel-derived $\mathrm{TiO}_{2}-\mathrm{SiO}_{2}$ implant coatings for direct tissue attachment. Part I: design, preparation and characterization," Journal of Materials Science, vol. 18, no. 9, pp. 1863-1873, 2007.

[26] V. V. Meretoja, A. E. De Ruijter, T. O. Peltola, J. A. Jansen, and T. O. Narhi, "Osteoblast differentiation with titania and titania-silica-coated titanium fiber meshes," Tissue Engineering, vol. 11, no. 9-10, pp. 1489-1497, 2005.

[27] V. Muhonen, S. Kujala, A. Vuotikka et al., "Biocompatibility of sol-gel-derived titania-silica coated intramedullary NiTi nails," Acta Biomaterialia, vol. 5, no. 2, pp. 785-793, 2009.

[28] V. V. Meretoja, T. Tirri, V. Ä̈ritalo, X. F. Walboomers, J. A. Jansen, and T. O. Närhi, "Titania and titania-silica coatings for titanium: comparison of ectopic bone formation within cellseeded scaffolds," Tissue Engineering, vol. 13, no. 4, pp. 855863, 2007.

[29] J. J. Yoo and S. H. Rhee, "Evaluations of bioactivity and mechanical properties of poly ( $\varepsilon$-caprolactone)/silica nanocomposite following heat treatment," Journal of Biomedical Materials Research-Part A, vol. 68, no. 3, pp. 401-410, 2004.

[30] X. Wang, R.A. Gittens, R. Song et al., "Effects of structural properties of electrospun $\mathrm{TiO}_{2}$ nanofiber meshes on their osteogenic potential," Acta Biomaterialia, vol. 8, no. 2, pp. 878885, 2012.

[31] B. Ding, H. Kim, C. Kim, M. Khil, and S. Park, "Morphology and crystalline phase study of electrospun $\mathrm{TiO}_{2}-\mathrm{SiO}_{2}$ nanofibres," Nanotechnology, vol. 14, no. 5, pp. 532-537, 2003.

[32] H. Chang, S. K. Kim, H. D. Jang, and S. W. Cho, "Effect of $\mathrm{SiO}_{2}$ nanoparticles on the phase transformation of $\mathrm{TiO}_{2}$ in micronsized porous $\mathrm{TiO}_{2}-\mathrm{SiO}_{2}$ mixed particles," Materials Letters, vol. 65, no. 21-22, pp. 3272-3274, 2011.

[33] D. D. Deligianni, N. Katsala, S. Ladas, D. Sotiropoulou, J. Amedee, and Y. F. Missirlis, "Effect of surface roughness of the titanium alloy Ti-6Al-4V on human bone marrow cell response and on protein adsorption," Biomaterials, vol. 22, no. 11, pp. 1241-1251, 2001.

[34] S. P. Xavier, P. S. P. Carvalho, M. M. Beloti, and A. L. Rosa, "Response of rat bone marrow cells to commercially pure 
titanium submitted to different surface treatments," Journal of Dentistry, vol. 31, no. 3, pp. 173-180, 2003.

[35] T. Fujita, Y. Azuma, R. Fukuyama et al., "Runx2 induces osteoblast and chondrocyte differentiation and enhances their migration by coupling with PI3K-Akt signaling," Journal of Cell Biology, vol. 166, no. 1, pp. 85-95, 2004. 

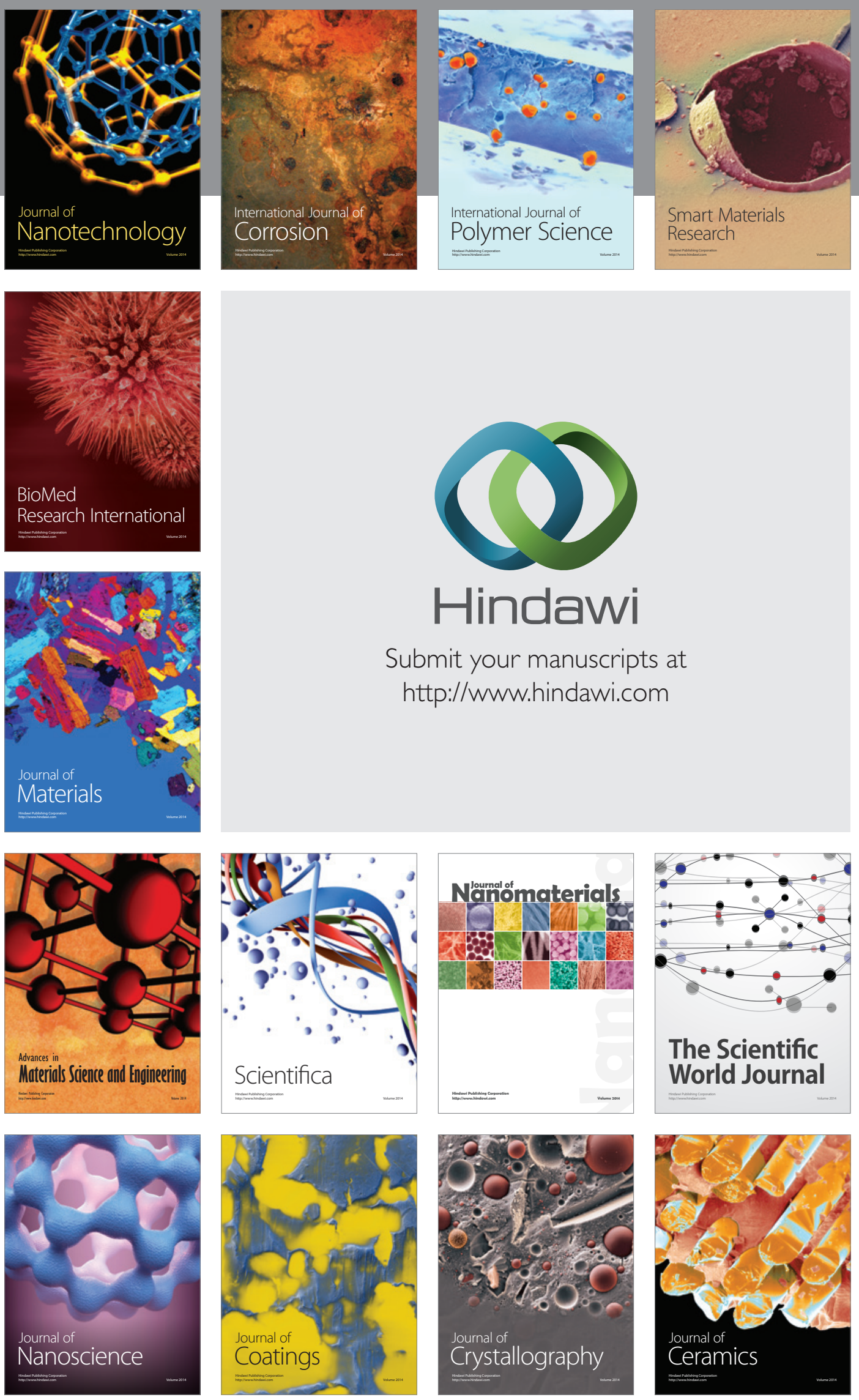

The Scientific World Journal

Submit your manuscripts at

http://www.hindawi.com

\section{World Journal}

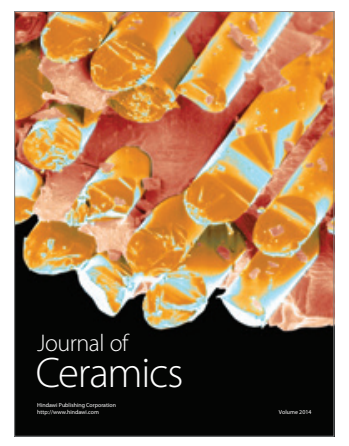

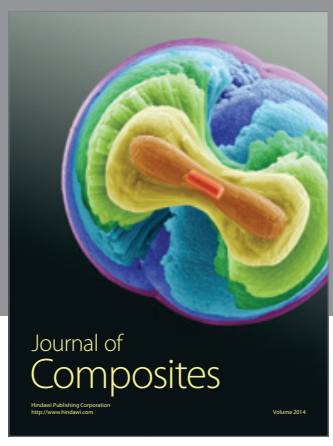
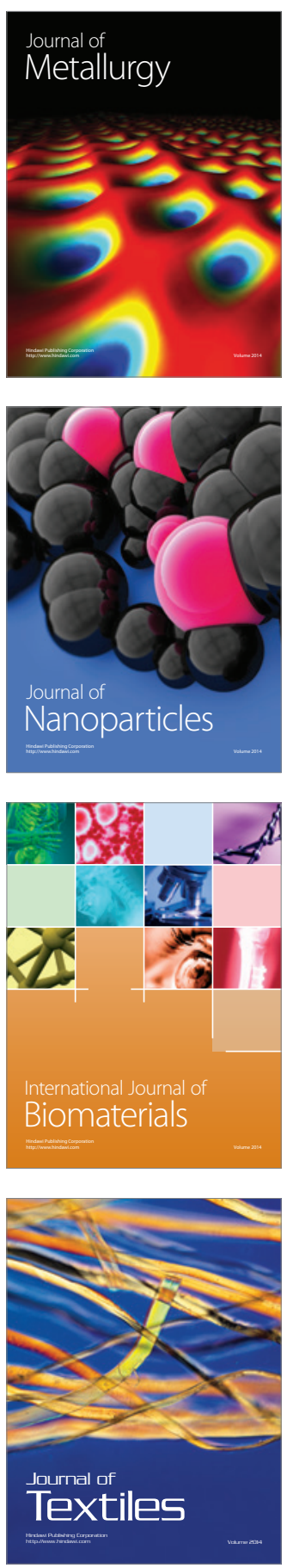